\title{
A Study on the Effects of Servovalve Lap on the Performance of a Closed - Loop Electrohydraulic Position Control System
}

\author{
Rafa A. H. AL-Baldawi Yahya A. Faraj \\ Al-Mustansiriya University-College of Eng. \\ Mechanical Eng. Department.
}

\author{
Rawand E. J. Talabani
}

University of Kirkuk \College of Eng. Petroleum Eng. Department.

\begin{abstract}
This paper deals with a closed-loop position control of a double acting and double-rod actuator using an electrohydraulic servovalve (EHSV). This system is studied by using symmetric critical center spool valve (zerolapped) and open center spool valve (underlapped). The nonlinear dynamic behavior of each case is undertaken and simulated. The system is modeled by using five state variables (piston position, piston velocity, actuator pressures, and servovalve spool displacement) and is tested under different step inputs. The EHSV is modeled with a first order differential equation. The closed-loop system stability is investigated by introducing equilibrium state into Jacobian matrix and determining the eignvalues. Viscous friction and compressibility of oil are included in the modeling of the system. Because the electrohydraulic position servo system is not very sensitive to coulomb friction and piston leakage they are neglected. The work showed that when the underlapped servovalve operates in the underlap region, the hydraulic position control system has more stable operation and better transient responses.
\end{abstract}

Keywords: Zerolap, Underlap, EHSV, Steady-State Characteristics, Dynamic Response, Position Control, Modeling, Simulation.

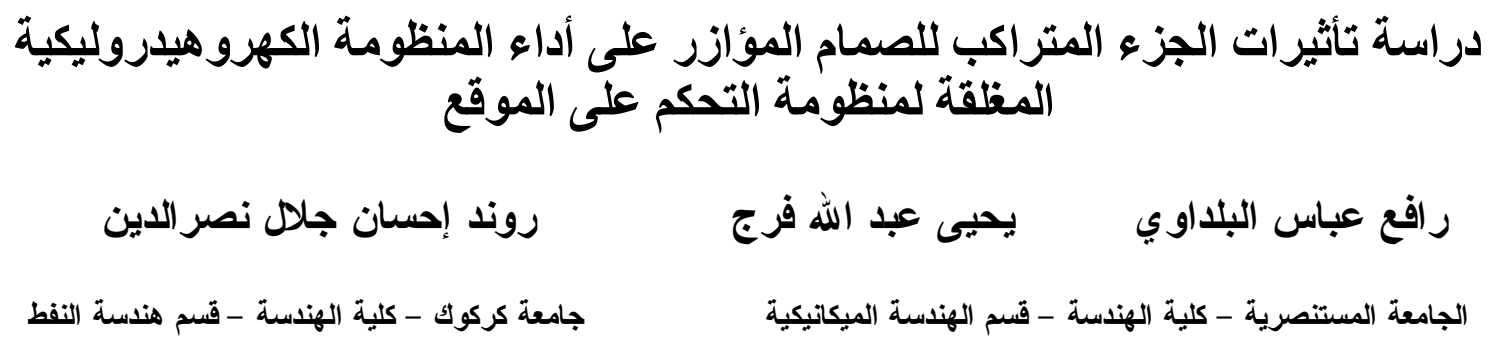

روند إحسان جلال نصر الاين

جامعة كركوك - كلية الهندسة - قسم هندسة النفط

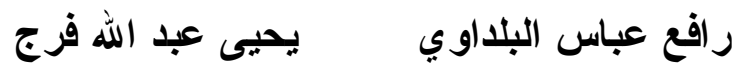

الجامعة المستنصرية - كلية الهنسة - قسم الهنسة الميكانيكية

\begin{abstract}
الخلاصة

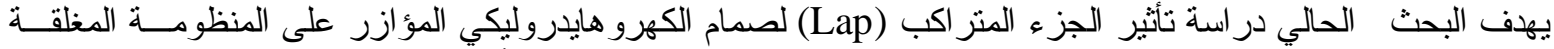

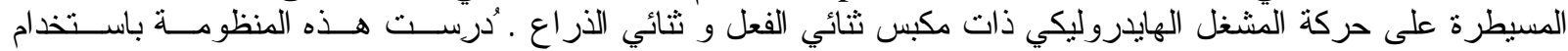

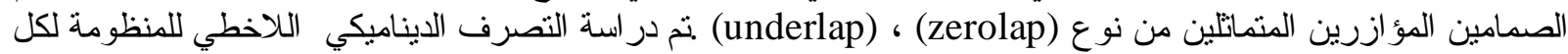

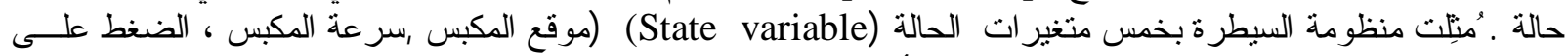

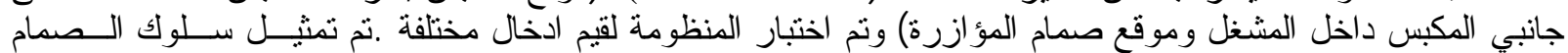

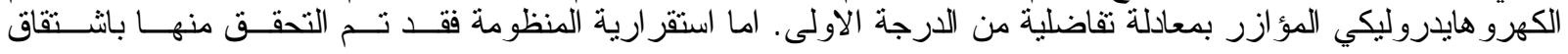

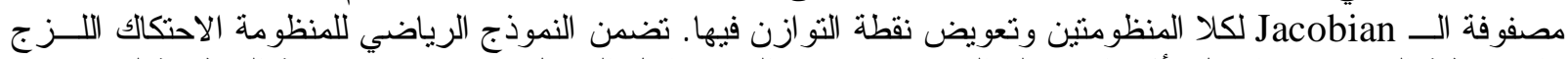

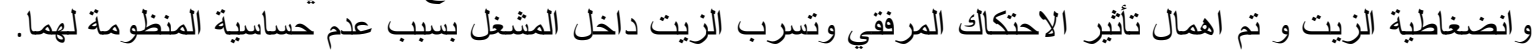

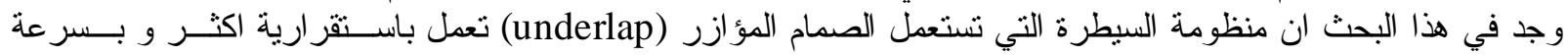
Received 14 August 2008 Accepted 31 Dec. 2008 


\section{Al-Rafidain Engineering $\quad$ Vol.17 $\quad$ No.5 $\quad$ October 2009}

\section{Introduction:}

Fluid power control, that is the transmission and control of energy by means of a pressurized fluid, is an old and well-recognized discipline. The growth of fluid power has accelerated with our desires to control ever increasing quantities of power and mass with higher speeds and greater precision. More specifically, where precise motion control is desired and space and weight are limited, the convenience of small size-to-high power ratios and the ability to apply very large forces and torques with fast response times, at the same time, achieve a high degree of both accuracy and performance to make the hydraulic servomechanism systems the ideal control elements. The demand to achieve more accurate and faster control at high power levels has produced an ideal marriage of hydraulic servomechanisms with electronic signal processing. Information could be transduced, generated, and processed more easily in the electronic medium than as pure mechanical or fluid signals, while the delivery of power at high speeds could be accomplished best by the hydraulic servo. This sophistication of electronic devices and hydraulic devices into electrohydraulic servomechanisms rendered better hydraulic systems, more efficient, more reliable, and faster equipments than ever before.

The key element in this family of mechanisms is the electrohydraulic servovalve. With a great power gains, the servovalve acts as a power amplifier that converts a low-power electrical signal into high-power hydraulic signal. These characteristics of electrohydraulic servo system make it very attractive for many applications, such as the control of industrial robots, processing of plastics, aircraft, satellites, launch vehicles, flight simulations, turbine control, and numerous military applications[1]. Because of the nonlinearity and uncertainty parameters in hydraulic systems (such as nonlinear flow/pressure characteristics, friction forces, flow forces and their effects on the spool position and unknown external disturbances) many researchers provid a nonlinear model of the hydraulic servo system control. A nonlinear model of electrohydraulic velocity servo system is introduced by Jovanoic [2]. In this paper; the flow nonlinearities, internal friction, oil compressibility, and valve dynamic (as first order transfer function) are presented. Lyapunov-based design is used to develop a nonlinear controller. He shows a good agreement between the analytical technique and experimental results. The work of Yun and Cho [3] has considered unknown load disturbance as parameter uncertainty and designed a Lyapunove-based controller to make the hydraulic system follows a given second order linear model. Rui [4] also develops a nonlinear model for single-stage electrohydraulic servovalve and produced a nonlinear controller based on backstepping approach. His work included the effects of frictions (dry, Coulomb, and viscous), valve dynamic, and oil compressibility. Servovalve dynamics play an important part on system behavior over a certain range of frequency response. Considerable efforts had been gone into modeling the electrohydraulic servovalve, which suggested that, depending on the frequency range of interest, a servovalve is best modeled by a first or second order transfer function [5,6]. Mookherjee [7] has used a computer-aided design and sensitivity analyses to study the effects of radial clearance, mismatch in the areas of the tractive air-gaps, and port geometry on the valve performance in a single-stage servovalve. His work included a nonlinear field modeling of hydraulic fluid in the spool valve and magnetic flux in the motor, showed qualitative conformity with the results presented in Moog technical Bulletin.

This work is concerned with studying the performance of a hydraulic servo position control system using zerolapped and underlapped spool servovalve. The work aims at studying the steady-state characteristics of the EHSV (zerolapped and underlapped) such as coefficients of valve flow gain, flow-pressure, and pressure sensitivity, determining and simulating a mathematical model for an electrohydraulic position servo control system, and finding out the influences of servovalve lap on the performance of the hydraulic position servomechanism. 


\section{Dynamic Models of Electrohydraulic System:}

Figure (1) shows a schematic of the actuatorlservovalve. As detailed by Merritt[8], the twostage electrohydraulic servovalve is comprised of a coil wrapped armature connected to a spool by a spring used for force feedback. The spool acts as a control valve, that regulates flow into the hydraulic actuator, which contains the two-actuator champers and a piston. The above control system can be modeled as follows:

\section{Servovalve Flow Equations:}

The flow through the servovalve, shown in figure (2a), can be compared to the flow of a fluid through a constricted point[9], as in figure (2b). The equation, which describes the flow through the valve, can be derived from Bernoulli's equation and the conservation of mass of the fluid as it moves through the constricted orifice[9]. The volumetric flow rate $Q$ through an orifice is given by:

$$
Q=C_{d} A_{0} \sqrt{\frac{2}{\rho}\left(P_{1}-P_{2}\right)}
$$

Where $C_{d}$ is the discharge coefficient of the orifice, $A_{0}$ is the area of the orifice, $\rho$ is the density of the fluid, and $P_{1}$ and $P_{2}$ are the respective pressure on either side of the orifice. The area $A_{0}$ varies linearly with the position of the spool, in case of critical center spool valve, the orifice area is only a function of spool position, $A_{0}=A_{0}\left(x_{v}\right)$ where $x_{v}$ is the valve spool displacement while in open center valve, the orifice area is a function of spool valve displacement and valve underlap, $\quad A_{0}=A_{0}\left(x_{v}, U\right)$, where $U$ is the valve underlap.

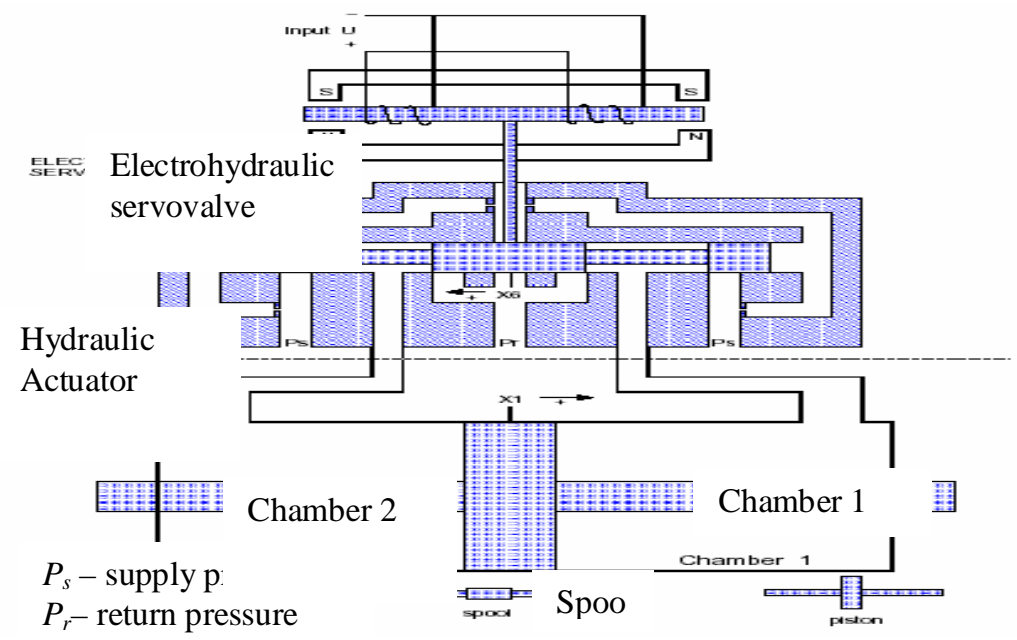

Figure (1): Detail of actuator/servovalve Pist
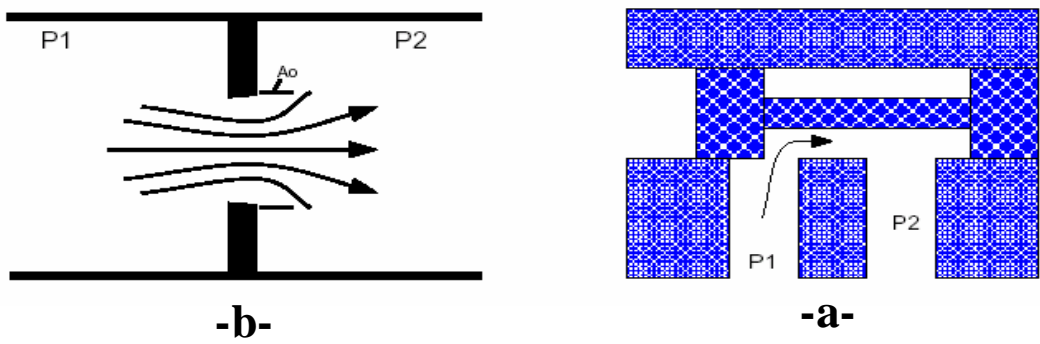

Figure (2): Flow through an office[9] 
For the critical center spool valve, the flow equations are, as shown in figure (3a), (neglecting the leakage flow rate):

$$
\begin{array}{ll}
Q_{1}=C_{d} w x_{v} \sqrt{\frac{2}{\rho}\left(\Delta P_{1}\right)}, & \Delta P_{1}=\left\{\begin{array}{cc}
P_{S}-P_{1} & x_{v}>0 \\
P_{1} & x_{v}<0
\end{array},\right. \\
Q_{2}=C_{d} w x_{v} \sqrt{\frac{2}{\rho}\left(\Delta P_{2}\right)}, & \Delta P_{2}=\left\{\begin{array}{cc}
P_{2} & x_{v}>0 \\
P_{S}-P_{2} & x_{v}<0
\end{array}\right.
\end{array}
$$

where $w$, which is called the area gradient of the valve, is the rate of change of orifice area with stroke (i.e. $A=w x_{v}$ ). For open center spool valve the flow equations, as shown in figure ( $3 \mathrm{~b}$ ), are (for underlap region only):

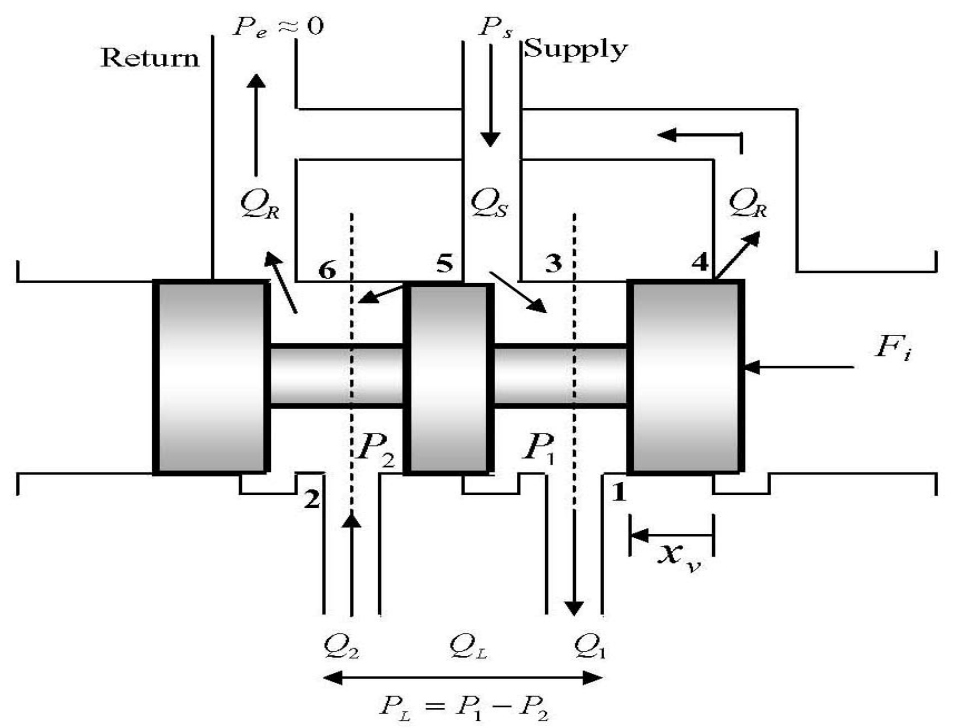

a-A typical three-land-four-way zerolapped spool valve with $x_{v}$ displacement

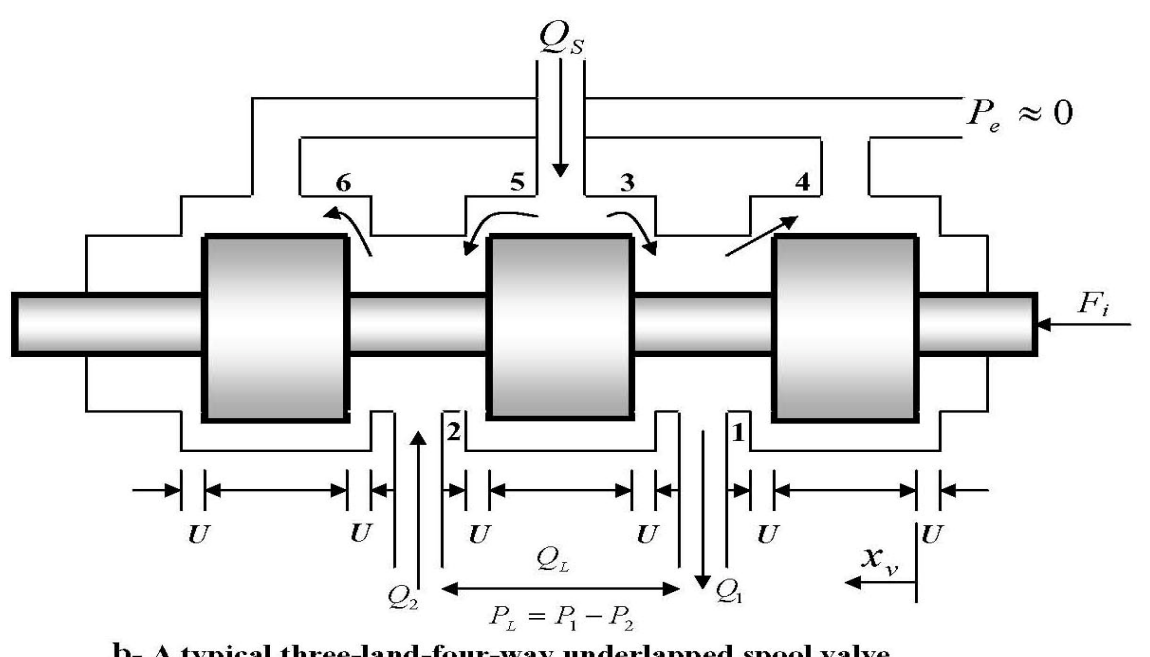

b- A typical three-land-four-way underlapped spool valve

Figure (3): Zerolapped \& underlapped Servovales. 
And for $x_{v} \geq 0$ :

$Q_{1}=C_{d} w\left[\left(U+x_{v}\right) \sqrt{\frac{2}{\rho}\left(P_{S}-P_{1}\right)}-\left(U-x_{v}\right) \sqrt{\frac{2}{\rho}\left(P_{1}\right)}\right]$,

$Q_{2}=C_{d} w\left[\left(U+x_{v}\right) \sqrt{\frac{2}{\rho}\left(P_{2}\right)}-\left(U-x_{v}\right) \sqrt{\frac{2}{\rho}\left(P_{S}-P_{2}\right)}\right]$,

And for $x_{v}<0$ :

$Q_{1}=C_{d} w\left[\left(U+x_{v}\right) \sqrt{\frac{2}{\rho}\left(P_{1}\right)}-\left(U-x_{v}\right) \sqrt{\frac{2}{\rho}\left(P_{S}-P_{1}\right)}\right]$,

$Q_{2}=C_{d} w\left[\left(U+x_{v}\right) \sqrt{\frac{2}{\rho}\left(P_{S}-P_{2}\right)}-\left(U-x_{v}\right) \sqrt{\frac{2}{\rho}\left(P_{2}\right)}\right]$.

If a matched and a symmetrical spool valve is used, $P_{1}=\left(P_{\mathrm{s}}+P_{L}\right) / 2$ and $P_{2}=(P \mathrm{~s}-P L) / 2$ can be used to write a general flow-pressure equations for both servovales in term of the supply pressure $\left(P_{s}\right)$ and the load pressure $\left(P_{L}\right)[5]$ as follows:

Zerolapped Servovalve:

$Q_{1}=Q_{2}=Q_{L}=\mathrm{C}_{d} w x_{v} \sqrt{\frac{1}{\rho}\left(P_{S}-\frac{x_{v}}{\left|x_{v}\right|} P_{L}\right)}$

Underlapped Servovalve:

$Q_{1}=Q_{2}=Q L=\mathrm{C}_{d} w\left[\left(U+x_{v}\right) \sqrt{\frac{1}{\rho}\left(P_{S}-P_{L}\right)}-\left(U-x_{v}\right) \sqrt{\frac{1}{\rho}\left(P_{S}+P_{L}\right)}\right]$

\section{Servovalve Coefficients:}

A general expression for the load flow is:

$$
Q_{L}=Q_{L}\left(x_{v}, P_{L}\right)
$$

If this function is expressed as a Taylor's series about a particular operating point $Q_{L}=Q_{L 1}$ and when the higher order infinitesimals is neglected, it can be written as:

$$
\Delta Q_{L}=\left.\frac{\partial Q_{L}}{\partial x_{v}}\right|_{1} \Delta x_{v}+\left.\frac{\partial Q_{L}}{\partial P_{L}}\right|_{1} \Delta P_{L}
$$

The partial derivatives required are obtained by differentiation of the pressure-flow equation. These partials define the two most important parameters of a valve.The flow gain is defined by:

$$
K_{g} \equiv \frac{\partial Q_{L}}{\partial x_{v}}
$$

and the flow-pressure coefficient Ks is defined by:

$$
K_{c} \equiv-\frac{\partial Q_{L}}{\partial P_{L}}
$$

Another useful quantity is the pressure sensitivity $K c$ defined by: 


$$
K_{t} \equiv-\frac{\partial P_{L}}{\partial x_{v}}
$$

which is related to the other quantity by the well-known relation from calculus:

$$
\frac{\partial P_{L}}{\partial x_{v}}=-\frac{\partial Q_{L} / \partial x_{v}}{\partial Q_{L} / \partial P_{L}} \quad \text { or } \quad K_{t}=\frac{K_{g}}{K_{c}}
$$

The coefficients $K_{g}, K_{c}$ and $K_{t}$ are called valve coefficients, that are extremely important in determining stability, frequency response, and other dynamic characteristics. The flow gain directly affects the loop gain constant in a system, therefore, it has a direct influence on system stability. The flow-pressure coefficient directly affects the damping ratio of valve- motor combinations, while the pressure sensitivity coefficient of valves is quite large, which accounts for the ability of valve-motor combinations to break away large friction loads with little error [8].

The values of valve coefficients vary with operating point. The most important operating point is the origin of the pressure-flow curves (i.e. $Q_{L}=P_{L}=x_{v}=0$ ), as in figure 4 , because system operation usually occurs near this region and the valve coefficients evaluated at this operating point are called the null valve coefficients [8].

\section{- Critical center spool valve coefficients}

The valve coefficients of an ideal zerolapped spool valve (leakage flow is zero) can be obtained by differentiation of equation. (4).

The flow gain is

$$
K_{g}=C_{d} w \sqrt{\frac{1}{\rho}\left(P_{S}-P_{L}\right)}
$$

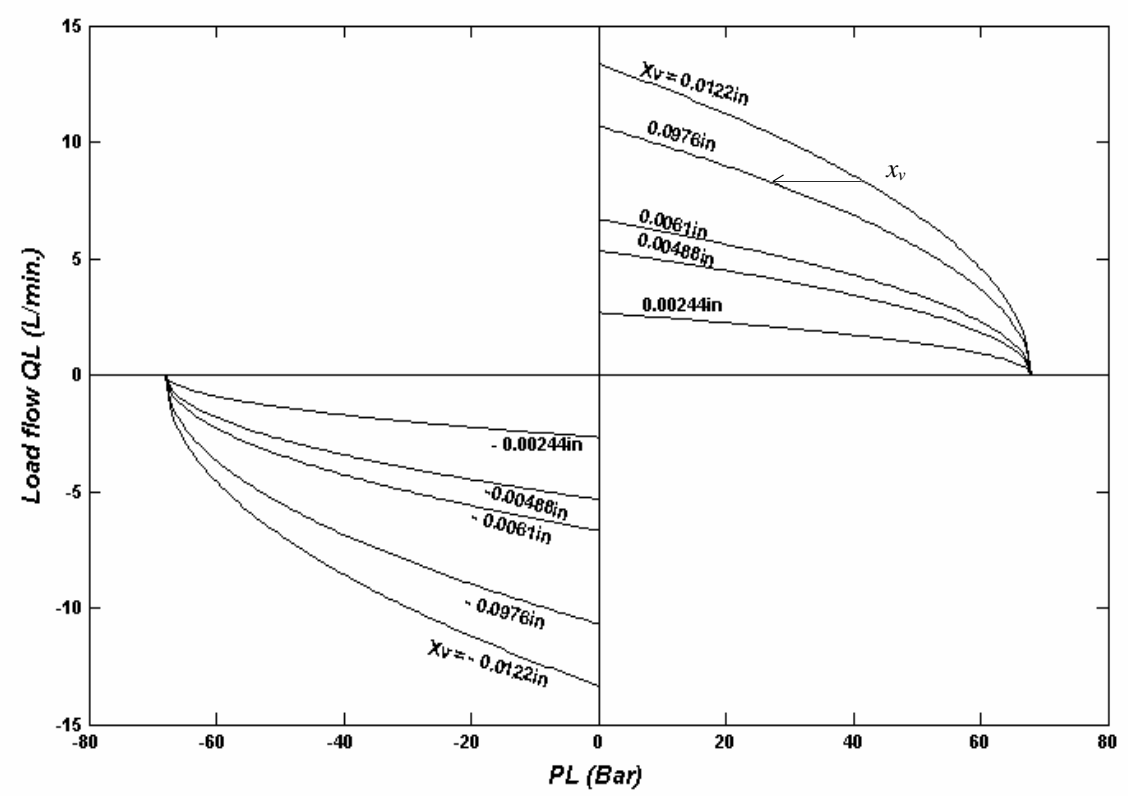

a- For zerolapped servovalve 


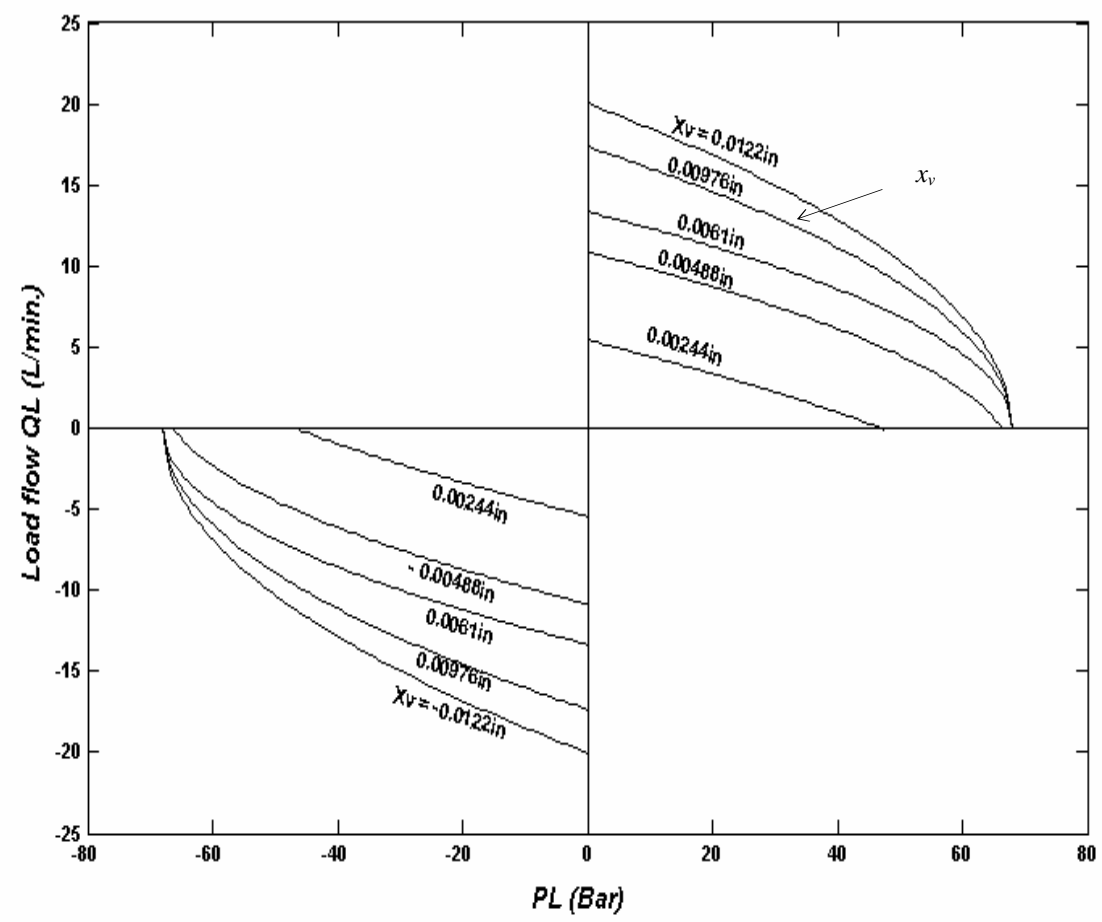

b- For underlapped servovalve

Figure (4): Servovalve pressure-flow characteristics for a supply pressure of $1000 \mathrm{pci}$

The flow pressure coefficient is :

$$
K_{c}=\frac{C_{d} w x_{v} \sqrt{\frac{1}{\rho}\left(P_{S}-P_{L}\right)}}{2\left(P_{S}-P_{L}\right)}
$$

and the pressure sensitivity is

$$
K_{t}=\frac{2\left(P_{S}-P_{L}\right)}{x_{v}}
$$

The null valve coefficients are:

$$
\begin{aligned}
& K_{g 0}=C_{d} w \sqrt{\frac{P_{S}}{\rho}} \\
& K_{c 0}=0 \\
& K_{t 0}=\infty
\end{aligned}
$$

- Open center spool valve coefficients

By differentiating esquation (5), the valve coefficients can be obtained for underlapped valve in the underlap region, and by evaluating the derivatives at $Q_{L}=P_{L}=x_{v}=0$, the null valve coefficients are: 


$$
\begin{aligned}
K_{g 0} & =2 C_{d} w \sqrt{\frac{P_{S}}{\rho}} \\
K_{c 0} & =\frac{C_{d} w U \sqrt{P_{S} / \rho}}{P_{S}} \\
K_{t 0} & =\frac{2 P_{S}}{U}
\end{aligned}
$$

\section{Flow Into and Out of the Actuator:}

The expression of the net flow into and out of the actuator consists of three terms:

1- Flow due to piston movement $A d x / d t$,

2- Flow due to laminar leakage across the piston, $C_{L} P_{L}$

3 - Flow due to compressibility of the working fluid.

Thus the flow rate $Q$ into the driving side of the actuator is:

$Q_{1}=\frac{\left(v_{01}+A_{1} x\right)}{\beta} \frac{d P_{1}}{d t}+A_{1} \frac{d x}{d t}+C_{L}\left(P_{1}-P_{2}\right)$

And the flow rate out of the actuator is:

$$
Q_{2}=-\frac{\left(v_{02}-A_{2} x\right)}{\beta} \frac{d P_{2}}{d t}+A_{2} \frac{d x}{d t}+C_{L}\left(P_{1}-P_{2}\right)
$$

where $v_{01}$ and $v_{02}$ are the initial volume of the driving and other sides of the linear actuator, $A_{1}=$ $A_{2}=A_{p}, A_{p}$ is surface area of piton head. $\beta$ is the bulk modulus of the fluid, and $C_{L}$ is leakage coefficient across the actuator head.

\section{Load Dynamic Equation:}

Many researchers have written the load equation in different forms. The most general form of the equation is[1, 9]:

$$
\left(P_{1}-P_{2}\right) * A_{P}=M \frac{d^{2} x}{d t^{2}}+\zeta \frac{d x}{d t}+F_{f c}\left(\frac{d x}{d t}\right)+K_{S} x+F_{d}
$$

where $\zeta$ is viscous friction constant, $F_{f c}$ is modeled coulomb friction force, $K_{S}$ is load spring constant, $M$ is the actuator and load mass, and $F_{d}$ is the external disturbance.

\section{Electrohydraulic Servovalve Equation:}

It is often convenient in servo analysis or in system synthesis work to represent an electrohydraulic servovalve by a simplified, equivalent transfer function[10]. If the effects of hysteresis and flow forces on the servovalve are neglected, then the dynamic behavior of the servovalve can be described by a first-order approximation[4], as follows:

$$
\dot{x}_{v}=-\frac{1}{\tau} x_{v}+\frac{K_{v}}{\tau} u
$$

where $x_{v}$ is valve spool displacement, $\tau$ is time constant of the servovalve, $K_{v}$ is servovalve gain, and $u$ is input current. 


\section{Al-Baldawi: A Study on the Effects of Servovalve Lap on the Performance of a Closed.....}

\section{Error Signal Equation:}

It can be seen from the block diagram of the control system, figure (5), that the summing amplifier differentially compares the input, and feedback voltage, which is obtained from the input and feedback potentiometers respectively; the resulting signal being fed to the amplifier. The output from the amplifier is used to move the spool of the electrohydraulic servovalve and subsequently move the load to its required position. If a potentiometer (input and feedback) gain $\left(K_{p}\right)$ and a servo amplifier gain $\left(G_{a}\right)$ are used, then the error current signal equation can be written as:

$u=K_{p} \cdot G_{a} \cdot\left(x_{\text {desired }}-x\right)$

In order to close the system model, it becomes necessary to replace the system input $u$ with equation (25); therefore, equation (24) is rewritten as:

$$
\dot{x}_{v}=-\frac{1}{\tau} x_{v}+\frac{K_{v}}{\tau}\left(K_{p} \cdot G_{a}\left(x_{\text {desired }}-x\right)\right)
$$

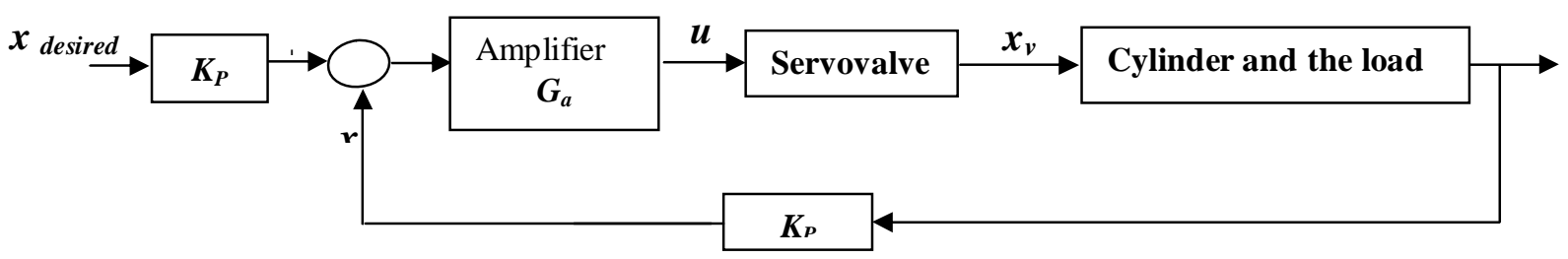

\section{Figure (5): EHSV Position control System}

\subsection{Derivation of the State Equations:}

A number of assumptions are made in order to simplify the dynamic model of the position control system. They are as follows:

1-The effect of Coulomb friction is neglected and it is assumed that there are no external disturbance and spring force.

2-The servovalve has a symmetrical spool, and the control is dominated to be within underlap region, i.e. $-U<x_{v}<U$ for underlapped spool.

3- The piston is located in the center of the actuator so that $v_{01}=v_{02}=v_{t} / 2=v_{0}$ and the piston leakage is neglected.

4- The hydraulic pump delivers a constant supply pressure.

Five state variables are used to describe the system operation. The first four state variables describe the operation of the hydraulic actuator: $x_{1}$ - the position of the piston $(x), x_{2}$ - the velocity of the piston $(d x / d t)$, and $x_{3} \& x_{4}$ - the pressures in the actuator chambers. The final state variable is from the servovalve: $x_{5}$ - the position of the control valve spool $\left(x_{v}\right)$. On the basis of the preceding assumptions and the state variables definitions, the equations of the closed-loop control system can be written as: 


\section{$\begin{array}{llll}\text { Al-Rafidain Engineering } & \text { Vol.17 } & \text { No.5 } & \text { October } 2009\end{array}$}

$$
\begin{aligned}
& \dot{x}_{1}=x_{2} \\
& \dot{x}_{2}=\left[\left(x_{3}-x_{4}\right) \cdot A_{p}-\zeta \cdot x_{2}\right] / m \\
& \dot{x}_{3}=\frac{\beta}{\left(v_{0}+A_{p} \cdot x_{1}\right)}\left[Q_{1}-A_{p} \cdot x_{2}\right] \\
& \dot{x}_{4}=\frac{\beta}{\left(v_{0}-A_{p} \cdot x_{1}\right)}\left[-Q_{2}+A_{p} \cdot x_{2}\right] \\
& \dot{x}_{5}=\frac{-1}{\tau} x_{5}+\frac{1}{\tau} K_{v} \cdot G a \cdot K_{p} \cdot\left(x_{\text {desired }}-x\right)
\end{aligned}
$$

Where equations. $(2 \& 3)$ are used for $Q_{1} \& Q_{2}$.

\subsection{System Stability:}

It is expected that the stability criteria of the linear systems could be applied to nonlinear systems, if the deviations from the equilibrium state are sufficiently small and the signals involved are small, therefore, the nonlinearity has only a minor effect. Thus a linearization principle can be used to determine the stability of nonlinear systems $[11,12]$.

The equilibrium state $x_{e}$ of the nonlinear unforced, $u=0$, autonomous system:

$$
\dot{x}=f\left(x_{e}\right)
$$

is asymptotically stable if the eigenvalues of the matrix:

$$
A=\left[\frac{\partial f(x)}{\partial x}\right]_{x=x_{e}}
$$

has negative real parts. It is unstable if at least one eigenvalue of $A$ has a positive real part. It is completely unstable if all eigenvalues of $A$ have positive real parts[12]. [ $\partial f(x) / \partial x]$ denotes the Jacobian matrix and equation (29) is called the linearized system of equation (28) about the equilibrium state $x_{e}$. The equilibrium state of the current hydraulic position servo control system described by the equation (10) (for both zerolapped \& underlapped), for zero input, is: $\left(x_{e}=x_{1}=\right.$ $\left.x_{2}=x_{5}=0\right) \&\left(x_{3}=x_{4}=P_{S} / 2\right)$

\section{Simulation Results: 3.1 System Response:}

The mass density of oil (the transmission medium used in hydraulic components) is a function of both pressure and temperature $\rho=f(\mathrm{P}, \mathrm{T})$. When one assumes a constant temperature and neglects the change in mass density $(\rho)$ due to change in pressure, a constant value of $(0.000078$ $I b-\sec ^{2} / \mathrm{in}^{4}$ ) can be considered for oil density. The data that had been used in the simulation are shown in tables (1) and (2). The displacement step responses obtained from the simulation for both critical and open center spool servovalves are shown in figure (4) with the step input signals of $0.1 \mathrm{in} . \& 0.3 \mathrm{in}$. amplitudes. The pressure responses for both sides of the driving cylinder are shown in figure (5) for zerolapped together with underlapped servovalve and the velocity responses for the actuator are shown in figures (6). 
Al-Baldawi: A Study on the Effects of Servovalve Lap on the Performance of a Closed.....

Table (1): HUM058-OBE Schneider two-stage servovalve parameters

\begin{tabular}{|l|l|l|l|}
\hline \multicolumn{1}{|c|}{ Symbol } & \multicolumn{1}{c|}{ Notation } & \multicolumn{1}{c|}{ Value } & \multicolumn{1}{c|}{ Unit } \\
\hline Rated flow at $\Delta P=1018.3 p c i$ & $Q_{\text {rate }}$ & 21.2 & Liter/min. \\
\hline Operating pressure & --- & $145.74-3055$ & pci \\
\hline Null leakage flow at $\Delta P=1018.3 p c i$ & $Q_{n l}$ & 0.742 & Liter/min. \\
\hline Rated input current & --- & $20 ; \pm 20$ & $\mathrm{~mA}$. \\
\hline Servovalve gain & $K_{v}$ & 0.955 & $\mathrm{in.} / \mathrm{A}$. \\
\hline Area gradient & $w$ & 0.513 & $\mathrm{in.} / \mathrm{in}$. \\
\hline Typical spool travel & $x_{\text {rate }}$ & 0.0191 & $\mathrm{in}$. \\
\hline Valve time constant & $\tau$ & 0.01 & $\mathrm{~s}$ \\
\hline & & & \\
\hline
\end{tabular}

Table (2): System parameters

\begin{tabular}{|c|c|c|c|}
\hline $\begin{array}{r}\text { Symbol } \\
\end{array}$ & Notation & Value & Unit \\
\hline Piston head inside diameter & $D i$ & 2.5 & in. \\
\hline Piston rod outside diameter & Dr & 1.375 & in. \\
\hline Surface area of piston & $A_{p}$ & 3.4238 & in. $^{2}$ \\
\hline Piston stroke & $\mathrm{Lt}$ & 6 & in. \\
\hline Current amplifier gain & $\mathrm{Ga}$ & 4 & $m A . / V$ \\
\hline Mass of piston and load & $\mathrm{M}$ & 1.1775 & lb.s $s^{2} /$ in. \\
\hline Viscous friction coefficient & $\xi$ & 100 & lb.s/in. \\
\hline Supply pressure & $\mathrm{P}_{\mathrm{s}}$ & 1000 & $p c i$ \\
\hline Mass density of hydraulic fluid & $\rho$ & 0.000078 & lb.s $\mathrm{s}^{2} \mathrm{in}^{4}$ \\
\hline Effective bulk modulus & $\beta$ & 200,000 & $l b / i^{2}$ \\
\hline Input and feedback (LVDT) gain & $\mathrm{K}_{\mathrm{p}}$ & 5.25 & V/in. \\
\hline
\end{tabular}

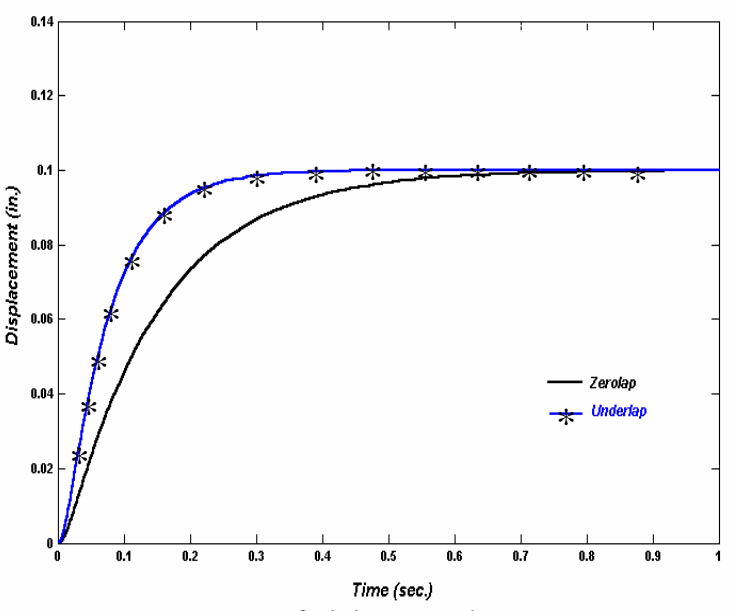

a- For 0.1 in. step input.

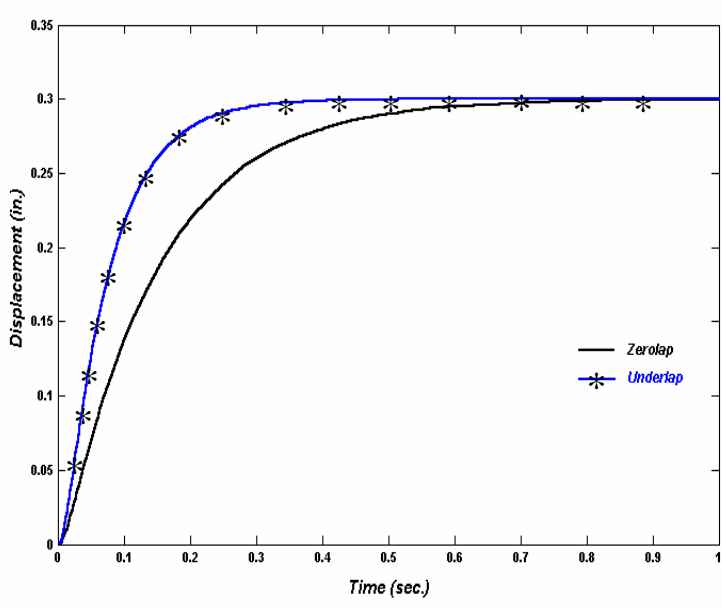

b- For 0.3 in. step input.

Figure (6): Position Transient Response 

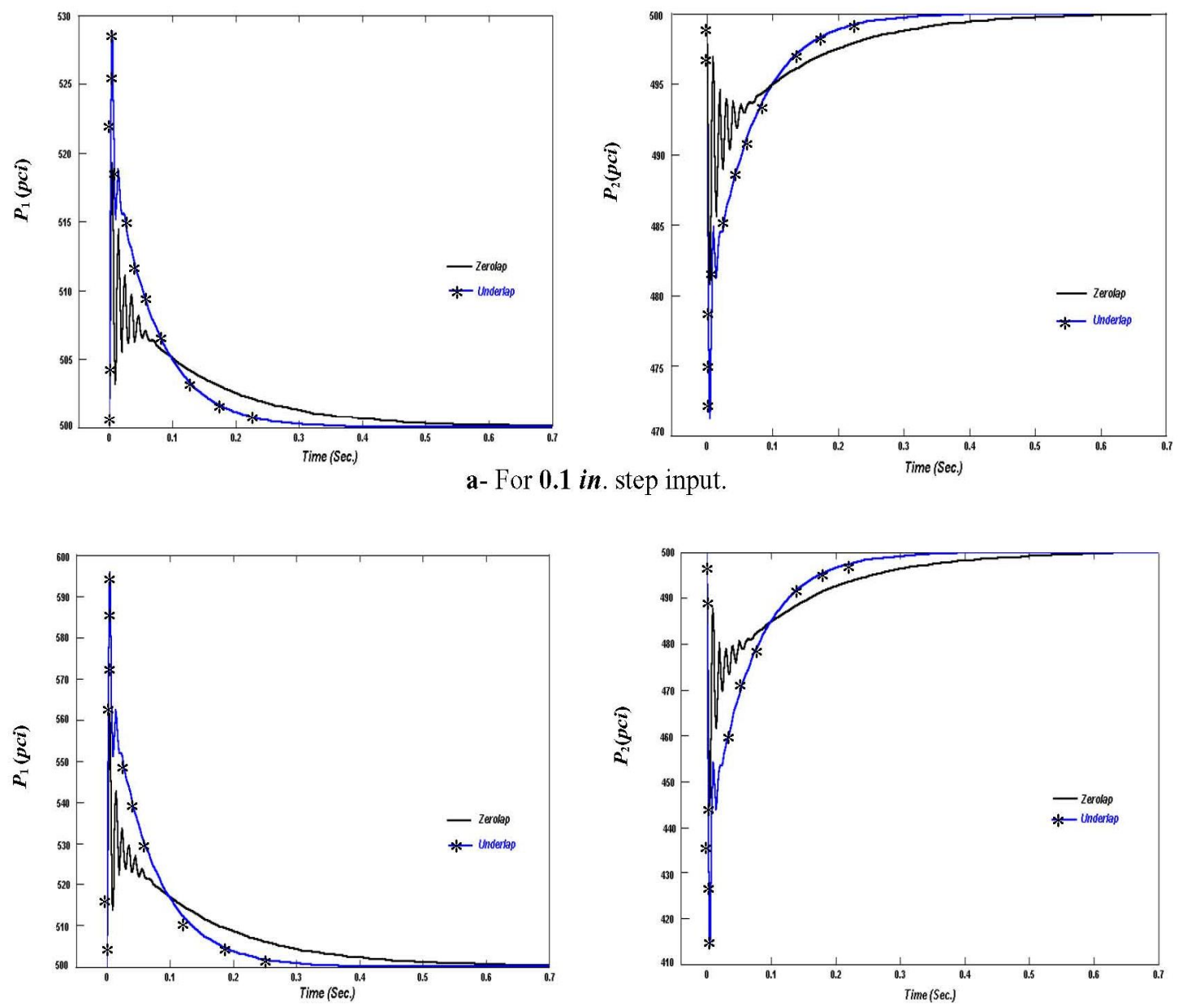

b- For $0.3 \mathrm{in}$. step input.

Figure (7): Pressure Transient Response

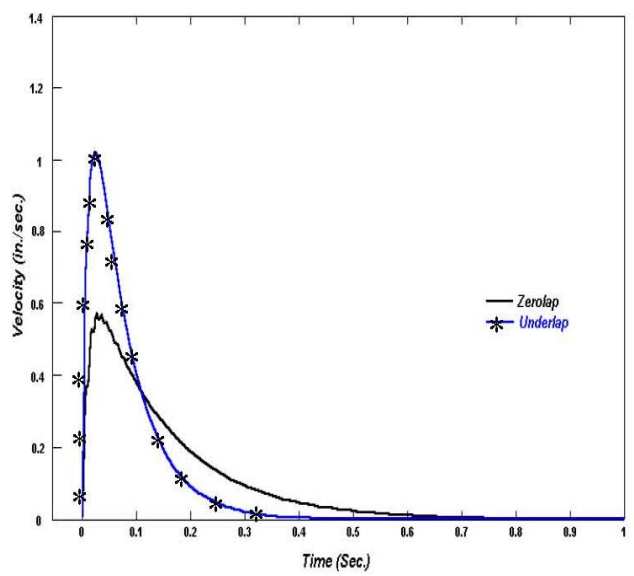

a- For 0.1 in. step input.

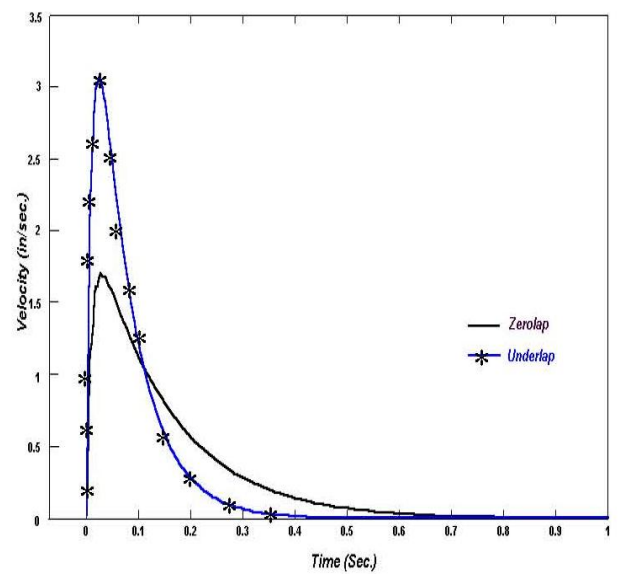

b- For $0.3 \mathrm{in}$. step input.

Figure (8): Velocity Transient Response 
Al-Baldawi: A Study on the Effects of Servovalve Lap on the Performance of a Closed.....

\subsection{System Stability :}

According to the theorem presented in section 2.2, the eigenvalues of the mathematical model, (equation.27) around the equilibrium state $x_{e}$ are shown in figure (9) and below.

For zerolapped servovalve system

$-1.47 e 001$

$-8.45 e 001$

$-2.66 e 002$

$-1.76 e 002+6.15 e 002 i$

$-1.76 e 002-6.15 e 002 i$

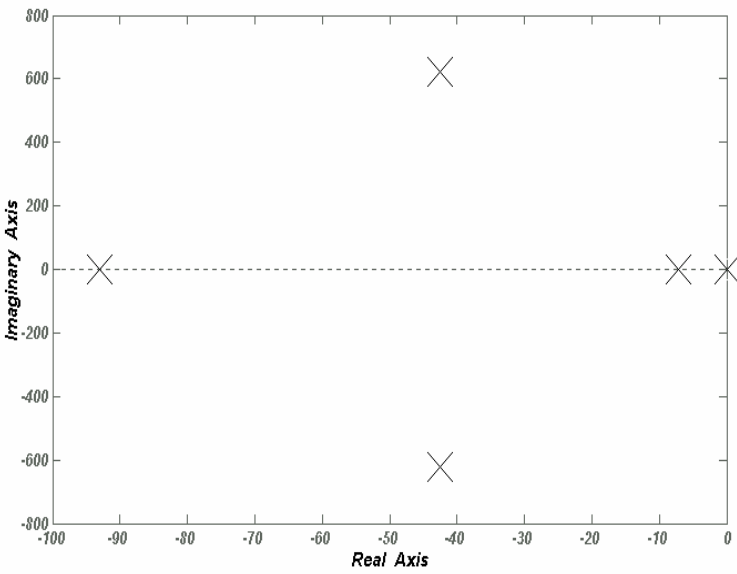

For zerolapped system
For underlapped servovalve system

$-5.84 e-044$

$-7.07 e 000$

$-9.30 e 001$

$-4.25 e 001+6.21 e 002 i$

$-4.25 e 001-6.21 e 002 i$

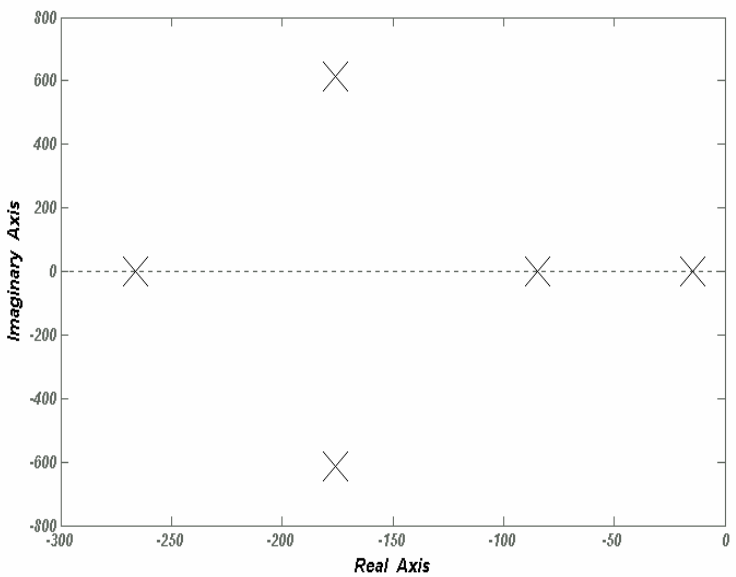

For underlapped system

Figure (9): Eigenvalues of closed-loop electrohydraulic position control system.

\section{Discussion:}

As the under lapped servo valve works in the under lap region (i.e. $\left|x_{v}\right| \leq U$ ), the position control system has dynamic results better than the same system with zero lapped servo valve. The servo valve flow gain has a direct influence on the system stability[8] and because the under lapped servo valve has a flow gain that is twice that of zero lapped servo valve, (eqs. $15 \& 18$ ), in the under lap region, therefore, the system with under lapped servo valve is relatively more stable as it can be noted in figure (9).The servo valve flow-pressure coefficient directly affects the damping ratio of the hydraulic system[8]; the under lapped servo valve has a greater flowpressure coefficient than the zero lapped servo valve, (eqs. 16 \& 19 ), therefore, the control system with under lapped servo valve has a damping ratio less than the control system with zero lapped servo valve (if the system is considered a linear system), so the position response of the control system, with under lapped servo valve, reaches the steady state faster than the system with zero lapped servo valve as shown in the figure (6) which also shows that the position control system (of both servo valves) has a second order behavior for position response to a step input with damping ratio $>1$. It can be seen in figures (7) that both sides steady-state cylinder's pressure are the same and equal to 0.5 of PS for both spool valves. It can also be seen that the 


$\begin{array}{llll}\text { Al-Rafidain Engineering } & \text { Vol.17 } & \text { No.5 } & \text { October } 2009\end{array}$

pressure responses of the system with under lapped servo valve are faster than the system with zero lapped servo valve (which is more oscillatory).

\section{Conclusion:}

The effects of servovalve lap on the performance of a closed - loop electrohydraulic position control system are studied. The related equations of the control system are derived and simulated using zerolapped and underlapped servovalve. Servovalve null coefficients are also determined. The study showed that when the underlapped servovalve operates in the underlap region, the position control system has more stable operation and better transient responses than the position control system with zerolapped servovalve and the control system has a second order behavior for displacement transient response to step input with $\eta>1$.

\section{References:}

[1]. Vilenius, M. J."The Application of Sensitivity Analysis to Electrohydraulic Position Control Servos" ASME Journal of Dynamic Systems, Measurements, and control, Vol. 105, No. 2, pp. 77-82, June 1983.

[2]. Jovanoic M. "Nonlinear Control of an Electrohydraulic Velocity Servosystem", University of California, 2001.

[3]. Yun, J. S., and Cho H. S., "Application of an Adaptive Model Following Control Technique to a Hydraulic Servo System Subjected to Unknown Disturbances" ASME Journal of Dynamic Systems, Measurement, and Control, Vol. 113, No. 3, pp.479-486, September 1991.

[4]. Rui L. "Nonlinear Control of Electro-hydraulic Servosystems: Theory and Experiment", Master degree thesis, University of Illinois, 1998.

[5] .Al-Baldawi R.A.H. "Optimum Performance of Electrohydraulic Position Control Systems Using an Underlapped Servovalve", Ph.D. Thesis, University of Wales College of Cardiff. October 1990.

[6]. Martin, D.J. and Burrows, C.R. "The Dynamic Characteristics of an Electro-hydraulic Servovalve" Trans of ASME, Journal of Dynamic System, Measurement and Control December 1976, pp 395.

[7]. Mookherjee S. "Design and Sensitivity Analysis of a Single-stage Electro-hydraulic Servovalve" Proc. of First FPNI-PhD Symposium Hamburg 2000, pp. 71-88.

[8]. Merritt, H. E. "Hydraulic control systems" John wiley and Sons, Inc., 1967.

[9]. Manhartsgruber B. "Application of Singular Perturbation Theory to Hydraulic Servo Drives-System Analysis and Control Design", Department of mechanics \& Machine Design, Johannes Kepler University.1998.

[10].Thayer W. J. "Transfer function for Moog servovalves" Technical Bulletin 103, Moog servocontrols Inc. New York, December 1958, Rev. January 1965.

[11]. Ogata K. "Modern Control Engineering” 4th Edition Prentice-Hall, Inc., 2001.

[12]. Willems J. L. "Stability Theory of Dynamical Systems" Thomas Nelson and Sons Lid. 1970.

The work was carried out at the college of Engg. University of Mosul 